\title{
Feasibility and SAFety of Long-Term Photodynamic Therapy (PDT) in the Palliative Treatment of Patients with Hilar Cholangiocarcinoma
}

\author{
A. Höblinger, T. Gerhardt, M.A. González-Carmona, R. Hüneburg, T. Sauerbruch, V. Schmitz \\ Department of Internal Medicine I, University of Bonn, Bonn, Germany
}

\begin{abstract}
Background and Aim: PDT is an important palliative option for patients with unresectable extrahepatic cholangiocarcinoma (CC). However, the results published to date reported on studies with no more than 6 (mostly up to 4) PDT procedures. Furthermore, the clinical experience of PDT in combination with chemotherapy is limited. The purpose of this retrospective analysis was to evaluate the feasibility and safety of multiple (4 to 14) settings of PDT, combined with biliary drainage, and (in some cases) with chemotherapy.

Methods: Ten patients with unresectable extrahepatic CC were treated with biliary stenting and at least 4 PDT procedures in our department between 10/2005 and $08 / 2010$.

Results: Ten patients (male/female $=5 / 5$ ), mean age 68.8 years (range, $54-81$ years) who received at least 4 PDT procedures were analyzed. All patients underwent endoscopic biliary drainage. Nine patients received metallic stents and one patient a plastic stent. In 4 patients $(40 \%)$ bilateral metal stenting (JoStent SelfX ${ }^{\mathbb{R}}$ ) was performed. The mean number of PDT sessions was $7.9 \pm 3.9$ (range: $4-14$ ). Eight patients had elevated bilirubin levels with a mean bilirubin at admission of $9.9 \pm 11.3 \mathrm{mg} / \mathrm{dL}$, which had decreased to an average minimum of $1.2 \pm 0.9 \mathrm{mg} / \mathrm{dL}$ after 3 months. No severe toxicity was noted. Two patients received concomitant chemotherapy (GEMCIS as $1^{\text {st }}$ line, GEMOX plus cetuximab as $2^{\text {nd }}$ line). The median overall survival has not been reached, whereas the estimated survival of all patients was 47.6 months, 95\% CI $25.9-48.1$

Conclusion: Long-term PDT in patients with extrahepatic CC is feasible and effective and is accompanied at least in this cohort- by a survival time of more than 2 years.
\end{abstract}

Key words: cholangiocarcinoma, palliative care, photodynamic therapy, chemotherapy

Abbreviations: $\mathrm{CC}=$ cholangiocarcinoma, $\mathrm{PDT}=$ photodynamic therapy

\section{INTRODUCTION}

Cholangiocarcinoma is the second most common primary hepatic malignancy, after hepatocellular carcino- ma [1]. Between 50 and 90 percent of patients with cholangiocarcinoma present with locally unresectable disease and their prognosis is poor. Relief of progressive biliary obstruction is one of the goals of palliative therapy. Photodynamic therapy (PDT) is an important palliative option for patients with unresectable extrahepatic cholangiocarcinoma [2]. It combines a photosensitizer such as Photofrin ${ }^{\circledR}$ with subsequent endoscopic application of red laser light $(630 \mathrm{~nm})$ to destroy cancer cells. The interaction between photosensitizer, light and oxygen causes tumor cell death, presumably by the generation of free oxygen radicals [3]. Improvements in survival time, biliary drainage and quality of life in patients with advanced extrahepatic cholangiocarcinoma have been reported in several uncontrolled studies and been confirmed in two randomised controlled trials [4-13]. PDT seems to be much better tolerated than chemotherapy and radiotherapy and can be repeated without leading to an accumulation of adverse events. However, the studies published so far dealt with a rather low number of PDT procedures (1 to 6, mostly 1 to 4). Furthermore, the clinical experience of PDT in combination with chemotherapy is limited.

The purpose of the present retrospective analysis was to evaluate the feasibility and safety of multiple (4 to 14) settings of photodynamic therapy, combined with biliary drainage and (in some cases) with chemotherapy.

\section{Patients And Methods}

\section{PATIENTS}

Ten patients with unresectable extrahepatic cholangiocarcinoma treated with at least 4 PDT procedures in the Department of Internal Medicine of the University Hospital Bonn between 10/2005 and 08/2010 were retrospectively analyzed (76 patients were treated with PDT in this period). The disease diagnosis was obtained by intraoperative biopsy in 2 patients, by endoscopic biopsy or brushing in 4 patients. In $4(40 \%)$ patients the diagnosis was based on data from computed tomography (CT) scan, magnetic resonance imaging (MRI), abdominal ultrasound, or endoscopic retrograde cholangiopancreatography (ERCP), and supported by growth of the tumor lesion during followup. Metastatic disease was present in 3 patients at the time of diagnosis (lymph nodes $\mathrm{n}=2$, peritoneal carcinomatosis $\mathrm{n}=1$ ). 


\section{BiLIARY Drainage}

All 10 patients underwent endoscopic biliary drainage. Three patients required transient external drainage (percutaneous drainage) and one patient received during the disease a combination of internal stenting and external-internal Yamakawa-type endoprosthesis (Pflugbeil, Zoemding, Germany) because of technical failure of the endoscopic way. The median number of endoscopic procedures per patient (excluding PDT procedures) was 3.

Endoscopic procedures were performed under analgetic sedation with midazolam and/or propofol and pethidin. 9 patients $(90 \%)$ received metallic stents, whereas one patient had plastic stent, which was regularly replaced. In 4 patients $(40 \%)$ bilateral metal stenting (JoStent SelfX ${ }^{\circledR}$, Abbott Vascular Deviced, Redwood City, CA, USA) was performed as described previously [16]. In 3 of them, bilateral stenting was performed at one endoscopic session and in one patient during two endoscopic procedures. One patient received $44 \mathrm{~mm}$ stents and one patient $68 \mathrm{~mm}$ stents bilaterally. In 2 patients a $44 \mathrm{~mm}$ stent was placed at the right and a $68 \mathrm{~mm}$ prothesis was placed at the left hepatic duct. Three patients received unilateral metal stenting: in 2 patients $68 \mathrm{~mm}$ JoStent SelfX ${ }^{\circledR}$ was placed at the right and in 1 patient a $44 \mathrm{~mm}$ prothesis was placed at the left hepatic duct. One patient who had cholangiocarcinoma of the common bile duct received a bare biliary Wallstent ${ }^{\circledR}$ (Boston Scientific, Natick, MA, USA), followed in a course of the disease by a placement of a covered $68 \mathrm{~mm}$ Wallstent. One patient received an uncovered Wallstent ${ }^{\circledR}$ at the right bile duct.

Oral ciprofloxacin therapy $500 \mathrm{mg}$ twice daily was started before ERCP and continued for 3 days. When there was evidence of cholangitis, bile was sent for culture and sensitivity testing.

\section{Photodynamic Therapy}

PDT was performed as described previously [8]. Patients received intravenous Photofrin (Axcan Pharma
Inc., Mount-Saint-Hilaire, Canada) at a dose of 2 $\mathrm{mg} / \mathrm{kg}$ bodyweight 48 hours before laser activation. One patient received after $7^{\text {th }}$ PDT-procedure Photofrin at the reduced dose of $1 \mathrm{mg} / \mathrm{kg}$ bodyweight because of the phototoxic skin reaction on the hands. PDT was performed 48 hours after sensitization with $630 \mathrm{~nm}$ light (Ceralas PDT 630 Diode Laser; CeramOptec GmbH, Bonn, Germany) at a light dose of $200 \mathrm{~J} / \mathrm{cm}$ length of stenosis (Fig. 1).

\section{CHEMOTHERAPY}

In 2 patients the photodynamic therapy was combined with chemotherapy. One patient received chemotherapy with gemcitabine and cisplatin (12 cycles). The second patient received combination therapy with gemcitabine and cisplatin (4 cycles) as $1^{\text {st }}$ line therapy, which was changed at tumor progress to gemcitabineoxaliplatin (GEMOX) plus cetuximab as 2nd line therapy (6 cycles) with subsequent change to gemcitanecisplatin (GEMCIS) plus cetuximab because of oxaliplatin-induced polyneuropathy. The time intervals of 2 weeks were kept between the PDT procedures and chemotherapy cycles in order to avoid cumulative adverse events.

\section{STATISTICAL ANALYSIS}

Results are expressed as arithmetic mean \pm SD. Statistical analysis was performed using the StatView 5.0 ${ }^{\mathrm{TM}}$ (Version for Windows; SAS Institute Inc., Cary, NC, USA) and SPSS software (SPSS Inc., Chicago, IL, USA). The Kaplan-Meier method was used to estimate overall survival outcomes. Overall survival was calculated from the first ERCP to the date of death or last follow-up.

\section{RESULTS}

\section{Patient Characteristics}

Ten patients (male/female $=5 / 5)$, mean age 68.8 years (range, $54-81$ years) which received at least 4 PDT

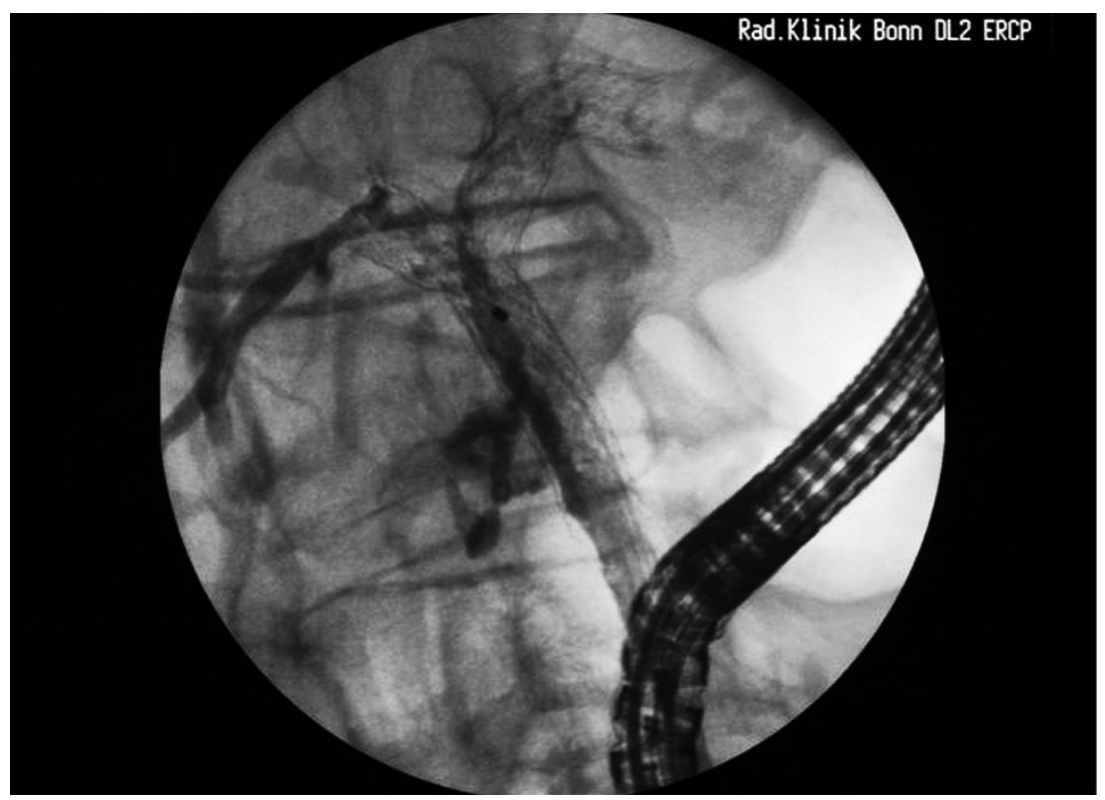

Fig. 1. 14th elective PDT in a 80 -yearold patient suffering from cholangiocarcinoma Bismuth stage IV. Bilaterally placement of JoStent SelfX was performed 2008 at the time of initial diagnosis. 
Table 1. Patient characteristics.

\begin{tabular}{lllllllll}
\hline Patient & Gender & $\begin{array}{l}\text { Age at } \\
\text { diagnosis }\end{array}$ & $\begin{array}{l}\text { Tumor } \\
\text { site }\end{array}$ & $\begin{array}{l}\text { Number of } \\
\text { PDT } \\
\text { procedures }\end{array}$ & $\begin{array}{l}\text { Chemo- } \\
\text { therapy }\end{array}$ & $\begin{array}{l}\text { Survival } \\
\text { (months) }\end{array}$ & $\begin{array}{l}\text { Status } \\
\text { Tumor } \\
\text { progression }\end{array}$ \\
\hline 1 & F & 71 & Hilum & 5 & No & 40.4 & Alive & Yes \\
2 & M & 78 & Hilum & 14 & No & 25.0 & Alive & Yes \\
3 & M & 60 & Hilum & 10 & No & 19,9 & Dead & - \\
4 & F & 81 & Hilum & 6 & No & 9.3 & Dead & - \\
5 & F & 63 & DHC & 5 & Yes & 17.5 & Alive & No \\
6 & F & 66 & Hilum & 4 & No & 47.6 & Dead & - \\
7 & M & 67 & Hilum & 13 & No & 25.1 & Alive & Yes \\
8 & F & 54 & Hilum & 6 & Yes & 12.6 & Alive & Yes \\
9 & M & 66 & Hilum & 12 & No & 31.0 & Alive & No \\
10 & M & 79 & Hilum & 4 & No & 30.9 & Dead & - \\
\hline
\end{tabular}

F, female; M, male.

procedures were analyzed. Of the 10 patients, 9 had hilar cholangiocarcinoma at stage Bismuth IV and one patient had cholangiocarcinoma of distal common bile duct. The clinical characteristics of this retrospective study population are summarized in Table 1. Metastases in regional lymph nodes were observed in tumors of $2(20 \%)$ patients whereas 1 patient had peritoneal carcinomatosis, confirmed by intraoperative biopsy.

\section{SAFETY}

The first PDT was performed after a mean time of $39.6 \pm 22.9$ days following the first ERCP procedure. The median number of PDT sessions was $6 /$ patient (range: 4 -14). In 4 patients the PDT was performed as soon as signs of tumor progression occurred and in 6 patients the PDT was performed at regular intervals of 1-2 months, even in the absence of tumor progression signs. The procedure was performed endoscopically in all patients. The primary adverse event after intervention was cholangitis in 2 patients $(20 \%)$, which was treated with antibiotics alone. In one patient, we performed subsequent PDT procedures without using a biliary contrast with no cholangitis episodes thereafter. One patient experienced skin phototoxicity World Health Organization grade I after the seventh PDT procedure. He was managed with topical therapy, no hospital readmission was required. We continued the PD'T with 50\% dosis reduction of Photofrin and observed no phototoxicity reactions after subsequent procedures. No other complications related specifically to PDT were noted.

\section{BILIARY DECOMPRESSION}

Two patients showed no hyperbilirubinemia at admission in our hospital due to primary intervention by the referring centre using plastic stents. Eight patients had elevated bilirubin levels with the mean bilirubin at admission of $9.9 \pm 11.3 \mathrm{mg} / \mathrm{dL}$. In this group the bilirubin level was successfully decreased: after 3 months a greater than $50 \%$ reduction was noted in 6 out of 8 $(75 \%)$ patients and the mean bilirubin level was $1.2 \pm$ $0.9 \mathrm{mg} / \mathrm{dL}$.

The mean number of cholangitis episodes was 3.3 \pm 3.4 per patient in the whole cohort, which was defined as fever $\left(>38^{\circ} \mathrm{C}\right)$ and right upper quadrant abdominal pain. No cholecystitis or liver abscesses were seen. One patient developed empyema of gall bladder, requiring cholecystectomy, but this complication occurred 5 months after PDT and is rather not related to photodynamic therapy or ERCP. One patient developed a chronic cholangitis caused by Pseudomonas aeruginosa, treated by a long-term administration of ertapenem.

\section{SURVIVAL}

The mean follow-up time was $27.98 \pm 11$ months. Four patients died during the follow-up because of tumor progression. The median overall survival has not been reached, the estimated survival (SPSS) was 47.6 months, 95\% CI 25.9 - 48.1 months. The survival data for all patients are shown in Table 1.

Tumor progression (growth of the hilar lesion, peritoneal carcinomatosis, liver and lymph node metastases) in the last imaging session was noted in 4 of the 7 patients who are still alive.

\section{Discussion}

Most patients with cholangiocarcinoma are diagnosed at an advanced stage, when treatment is essentially palliative. Improvements in biliary drainage, survival time and quality of life in patients with advanced CC have been reported in several uncontrolled studies and been confirmed in two randomised controlled trials [4-15]. In the first RCT of 39 patients with large $(>3 \mathrm{~cm})$ hilar tumors, Ortner et al. demonstrated superior median survival (493 vs 98 days, $\mathrm{p}<0.0001$ ), improved biliary drainage and improvement of Karnofski performance status in the PDT group [9]. This study included only patients with a bilirubin decrease of less than 
Table 2. Studies on photodynamic therapy in unresectable cholangiocarcinoma.

\begin{tabular}{lllllll}
\hline Study & Year & Study type & $\begin{array}{l}\text { Number } \\
\text { of patients }\end{array}$ & $\begin{array}{l}\text { Mean PDT } \\
\text { sessions (range) }\end{array}$ & $\begin{array}{l}\text { Median } \\
\text { survival (months) }\end{array}$ & $\begin{array}{l}\text { Adverse events: } \\
\text { phototoxicity, cholangitis }\end{array}$ \\
\hline Ortner & 1998 & Single arm & 9 & $1.5(1-2)$ & 14.6 & $1(11 \%), 0(0 \%)$ \\
Berr & 2000 & Single arm & 23 & $3(1-5)$ & 11.1 & $3(13 \%), 8(35 \%)$ \\
Zoepf & 2001 & Single arm & 8 & $1-2$ & 4 & $0,2(25 \%)$ \\
Rumalla & 2001 & Single arm & 6 & $2.3(1-2)$ & $>6$ & $2(33 \%), 2(33 \%)$ \\
Dumoulin & 2003 & Single arm & 24 & $1-2$ & 9.9 & $2(8 \%), 5(21 \%)$ \\
Ortner & 2003 & Randomized & 39 & $2.4(1-5)$ & 16.4 & $2(10 \%), 5(25 \%)$ \\
Ortner & 2003 & Nonrandomized & 31 & $1.5(1-4)$ & 14.2 & $3(10 \%), 6(19 \%)$ \\
Harewood & 2005 & Single arm & 8 & $2(1-5)$ & 9.2 & $2(25 \%), 2(25 \%)$ \\
Shim & 2005 & Single arm & 24 & $1-4$ & 18.6 & $1(4 \%))$ liver abscess \\
Zoepf & 2005 & Randomized & 32 & $1-3$ & 20.6 & $0,4(25 \%)$ \\
Witzigmann & 2006 & Single arm & 68 & $2(1-6)$ & 12 & $8(12 \%), 38(56 \%)$ \\
Prasad & 2007 & Single arm & 25 & $1.6(1-4)$ & 13.4 & $1(4 \%), 2(8 \%)$ \\
Fuks & 2009 & Single arm & 14 & $2(1-4)$ & 13.8 & $2(14 \%), 8(57 \%)$ \\
This study & 2010 & Single arm & 10 & $8(4-14)$ & $>25$ & $1(10 \%), 2(20 \%)$ \\
\hline
\end{tabular}

$50 \%$ after biliary stenting and was therefore criticized on grounds of potential bias. The second prospective randomised trial included 32 unselected nonresectable patients, especially those with successful biliary drainage, and confirmed the survival advantage in the PDT group (630 vs 210 days, $p=0.019$ ) [12]. Perfomance status did not improve, but remained constant during the whole observation period. Witzigmann et al. have analyzed prospectively treatment and outcome data of 184 patients with hilar cholangiocarcinoma, treated with either surgery, stenting alone or PDT plus stenting. This study showed similar survival time of patients treated with PDT to that of patients with incomplete R1-R2 resection (366 days), but with a considerably lower rate of complications [13].

As shown in Table 2, most clinical studies on PDT for cholangiocarcinoma performed a rather limited (mostly 1 to 4) number of PDT procedures. This is the first clinical report of a long-term repeat photodynamic therapy $(4-14$ procedures $)$ in patients with inoperable CC. Furthermore, two patients were successfully treated with the combination of PDT and chemotherapy. Compared to the previously reported median survival times of about 14-20 months in the most studies and the median survival of 16.5 months in our own recently published cohort of patients treated with 1 to 4 PDT procedures [17], the patients of this study showed an impressive estimated survival of 47.6 months, despite having locally advanced or metastatic disease. Tumor destruction by PDT is not only a result of apoptosis or necrosis of cancer cells via generation of reactive oxygen species. PDT also induces secondary events including microvascular disruption and local active inflammation. Moreover, although PDT was originally considered a local treatment, several studies have shown that PDT leads to enhancement of anti-tumor immunity [14]. Further evaluation whether enhanced immune responses contribute to improved local or systemic tumor control requires well-designed clinical trials with large enough patient populations to provide statistical relevance and correlative immunologic endpoints.

Recently, factors associated with increased survival after PDT were analyzed in a retrospective study of 25 patients with unresectable CC treated with PDT in addition to biliary decompression [15]. The presence of a visible mass on imaging studies, a lower serum albumin level and increasing time between diagnosis and PDT predicted a poorer survival rate. This study indicates the importance of early treatment with PDT after diagnosis of unresectable CC. In our cohort the first PDT was performed after a mean time of 39.6 [14-84] days following the first ERCP procedure. This time interval is longer than in most previous published studies.

The major adverse effects of PDT include photosensitivity caused by retention of photosensitizers by the skin (in case of Photofrin ${ }^{\circledR}$, phototoxicity of 4-6 weeks) and local complications such as cholangitis, bilioma, liver abscess and hemobilia. Two patients in our study developed cholangitis after PDT which required prolonged hospitalization and was mainly associated with the endoscopic procedure. We did not observe any severe phototoxicity (Grade III) or other adverse events directly related to PDT.

Two patients in our study received combination of PDT with systemic chemotherapy, which was well tolerated without cumulation of adverse effects. This is in concordance with the report from Fuks and with our own recently published results.

In conclusion, our present study demonstrates that long-term repeat photodynamic therapy with multiple PDT procedures is feasible and safe in patients with unresectable extrahepatic cholangiocarcinoma. The more aggressive treatment strategy combining PDT with systemic chemotherapy is well tolerated and can be safely performed in selected patients. Further studies are necessary to evaluate the effect of PDT in combination with chemotherapy on survival, which may become a gold standard of care for palliation of cholangiocarcinoma. 
Conflicts of interest: None

\section{REFERENCES}

1. Aljiffry M, Walsh MJ, Molinari M. Advances in diagnosis, treatment and palliation of cholangiocarcinoma: 19902009. World J Gastroenterol. 2009 Sep 14; 15(34): 424062.

2. Ortner MA. Photodynamic therapy for cholangiocarcinoma: overview and new developments. Curr Opin Gastroenterol. 2009 Sep; 25(5): 472-6.

3. Juarranz A, Jaén P, Sanz-Rodríguez F, Cuevas J, González S. Photodynamic therapy of cancer. Basic principles and applications. Clin Transl Oncol. 2008 Mar; 10 (3): 148-54.

4. Ortner MA, Liebetruth J, Schreiber S, Hanft M, Wruck U, Fusco V, Müller JM, Hörtnagl H, Lochs H. Photodynamic therapy of nonresectable cholangiocarcinoma. Gastroenterology. 1998 Mar; 114(3): 536-42.

5. Berr F, Wiedmann M, Tannapfel A, Halm U, Kohlhaw KR, Schmidt F, Wittekind C, Hauss J, Mössner J. Photodynamic therapy for advanced bile duct cancer: evidence for improved palliation and extended survival. Hepatology. 2000 Feb; 31(2): 291-8.

6. Zoepf T, Jakobs R, Arnold JC, Apel D, Rosenbaum A, Riemann JF. Photodynamic therapy for palliation of nonresectable bile duct cancer--preliminary results with a new diode laser system. Am J Gastroenterol. 2001 Jul; 96(7): 2093-7.

7. Rumalla A, Baron TH, Wang KK, Gores GJ, Stadheim LM, de Groen PC. Endoscopic application of photodynamic therapy for cholangiocarcinoma. Gastrointest Endosc. 2001 Apr; 53(4): 500-4.

8. Dumoulin FL, Gerhardt T, Fuchs S, Scheurlen C, Neubrand M, Layer G, Sauerbruch T. Phase II study of photodynamic therapy and metal stent as palliative treatment for nonresectable hilar cholangiocarcinoma. Gastrointest Endosc. 2003 Jun; 57(7):860-7.

9. Ortner ME, Caca K, Berr F, Liebetruth J, Mansmann U, Huster D, Voderholzer W, Schachschal G, Mössner J, Lochs H. Successful photodynamic therapy for nonresectable cholangiocarcinoma: a randomized prospective study. Gastroenterology. 2003 Nov; 125(5):1355-63.

10. Harewood GC, Baron TH, Rumalla A, Wang KK, Gores GJ, Stadheim LM, de Groen PC. Pilot study to assess patient outcomes following endoscopic application of photodynamic therapy for advanced cholangiocarcinoma. J Gastroenterol Hepatol. 2005 Mar; 20(3):415-20.

11. Shim CS, Cheon YK, Cha SW, Bhandari S, Moon JH, Cho YD, Kim YS, Lee LS, Lee MS, Kim BS. Prospective study of the effectiveness of percutaneous transhepatic photodynamic therapy for advanced bile duct cancer and the role of intraductal ultrasonography in response assessment. Endoscopy. 2005 May; 37(5): 425-33.
12. Zoepf T, Jakobs R, Arnold JC, Apel D, Riemann JF. Palliation of nonresectable bile duct cancer: improved survival after photodynamic therapy. Am J Gastroenterol. 2005 Nov; 100(11): 2426-30.

13. Witzigmann H, Berr F, Ringel U, Caca K, Uhlmann D, Schoppmeyer K, Tannapfel A, Wittekind C, Mossner J, Hauss J, Wiedmann M. Surgical and palliative management and outcome in 184 patients with hilar cholangiocarcinoma: palliative photodynamic therapy plus stenting is comparable to $\mathrm{r} 1 / \mathrm{r} 2$ resection. Ann Surg. 2006 Aug; 244(2): 230-9.

14. Gollnick SO and Brackett CM. Enhancement of anti-tumor immunity by photodynamic therapy. Immunol Res. 2010 Mar; 46(1-3):216-26.

15. Prasad GA, Wang KK, Baron TH, Buttar NS, Wongkeesong LM, Roberts LR, LeRoy AJ, Lutzke LS, Borkenhagen LS. Factors associated with increased survival after photodynamic therapy for cholangiocarcinoma. Clin Gastroenterol Hepatol. 2007 Jun; 5(6):743-8.

16. Fuks D, Bartoli E, Delcenserie R, Yzet T, Celice P, Sabbagh C, Chatelain D, Joly JP, Cheron N, Dupas JL, Regimbeau JM. Biliary drainage, photodynamic therapy and chemotherapy for unresectable cholangiocarcinoma with jaundice. J Gastroenterol Hepatol. 2009 Nov; 24(11): 1745-52.

17. Gerhardt T, Rings D, Höblinger A, Heller J, Sauerbruch $\mathrm{T}$, Schepke M. Combination of bilateral metal stenting and trans-stent photodynamic therapy for palliative treatment of hilar cholangiocarcinoma. Z Gastroenterol. 2010 Jan; 48(1): 28-32.

18. Juntermanns B, Radunz S, Heuer M, Hertel S, Reis H, Neuhaus JP, Vernadakis S, Trarbach T, Paul A, Kaiser GM. Tumor markers as a diagnostic key for hilar cholangiocarcinoma. Eur J Med Res. 2010 Aug 20;15(8):357-61.

Received: February 18, 2011 / Accepted: May 25, 2011

Address for correspondence:

Aksana Höblinger, MD

Department of Internal Medicine I

University of Bonn

Sigmund Freud Strasse 25

D-53105 Bonn

Germany

Tel.: $\quad+49-228-287-15507$

Fax: +49-228-287-15489

E-mail: aksana.hoeblinger@ukb.uni-bonn.de 